\title{
Emergence of qualia from brain activity or from an interaction of proto- consciousness with the brain: which one is the weirder? Available evidence and a research agenda
}

\author{
Patrizio Tressoldi* ${ }^{1}$, Enrico Facco ${ }^{2}$, and Daniela Lucangeli ${ }^{3}$ \\ ${ }^{1}$ Dipartimento di Psicologia Generale, Università di Padova, Padova, Italy \\ ${ }^{2}$ Department of Neurosciences, Università di Padova, Padova, Italy \\ ${ }^{3}$ DPSS, Università di Padova, Padova, Italy \\ *Corresponding author's e-mail address: patrizio.tressoldi@unipd.it
}

Published online: 16 August 2016 (version 1)

Cite as: P. Tressoldi et al. 2016 (DOI: 10.14293/S2199-1006.1.SOR-SOCSCI.AY054B.v1)

Reviewing status: The review of this article was author-mediated. The ScienceOpen editorial office has verified and confirmed the identities of the reviewers. The endorsement statement and reviewers names are provided below. The article is also available for continuous post-publication peer review on its dedicated ScienceOpen homepage.

\section{Peer Review by Endorsement Statement:}

"I have read this article, given feedback to the authors and now feel that it is of appropriate quality to be included in the scientific literature and be part of the open scientific discourse."

Mario Beauregard, PhD

Senior Research Associate

Laboratory for Advances in Consciousness and Health

Department of Psychology, University Arizona

Dr. David Vernon

Canterbury Christ Church University

School of Psychology, Politics and Sociology

Primary Discipline: Social \& Behavioral Sciences Secondary Discipline: Medicine, Psychology, Theoretical physics Keywords: Qualia, Consciousness, Brain, Mind, Quantum Physics

\section{ABSTRACT}

This contribution to the science of consciousness aims at comparing how two different theories can explain the emergence of different qualia experiences: meta-awareness, metacognition, the placebo effect, out-of-body experiences, cognitive therapy, meditation-induced brain changes, etc. The first theory postulates that qualia experiences derive from specific neural patterns, and the second one that qualia experiences derive from the interaction of a proto-consciousness with the brain's neural activity. From this comparison, it will be possible to judge which one seems to better explain the different qualia experiences and to offer a more promising research agenda.

\section{INTRODUCTION}

Consciousness, mind, the whole psyche, and soul have been one of the most relevant and puzzling problems since the origin of philosophy and psychology. The speculations on their nature date back to pre-Socratic philosophers (like Pitagoras) in the West, as well as Veda tradition, Yoga, and Buddhism in the East.
Prof. Markus Maier

Ludwig-Maximilians-Universität München

Department Psychologie

Allgemeine Psychologie II
A huge interest on consciousness has raised up in the last three decades, and a wealth of data on its neurophysiological, physical, molecular, psychological, and behavioral aspects is now available in the literature (e.g., Churchland, 2013; Cohen \& Schooler, 2014; Dehaene, 2014). Consciousness is not a strictly medical topic but encompasses the fields of psychology, biology, physics, as well as epistemology and philosophy with an increasing need of interdisciplinary efforts and exchange of ideas.

The complexity of the problem and the width of involved fields of knowledge suggest the need for an open-minded approach, able to avoid any inadvertently prejudicial, dogmatic stance, based on one's formation and beliefs. It also prevents one to properly discuss the whole topic within the space of an article. Therefore, the aim here is only to compare the interpretation of a series of phenomena listed in Table 1, from two different theoretical approaches.

In this article, we will use the term "Qualia" (Q) as referring to the first-person conscious awareness of both physical and mental information, for example, "I see a red rose", "I feel happy" (Michael, 2015). These phenomenological reports can 
Table 1. Local Q experiences.

\begin{tabular}{|c|c|c|}
\hline Q Experiences & Mind = Brain & Proto-consciousness $(\mathrm{PC}) \leftrightarrow$ Brain \\
\hline $\begin{array}{l}\text { 1. Cognitive therapy-induced brain changes } \\
\text { (Messina, Sambin, Palmieri, \& } \\
\text { Viviani, 2013) }\end{array}$ & $\begin{array}{l}\text { Brain correlates of therapist suggestions change } \\
\text { brain correlates of emotional, behavioral, and } \\
\text { other dysfunctions. }\end{array}$ & $\begin{array}{l}\text { PC realizes Qs following the } \\
\text { therapeutic suggestions changing } \\
\text { their neural substrate }\end{array}$ \\
\hline $\begin{array}{l}\text { 2. Meditation-induced brain changes (Tang, } \\
\text { Hölzel, \& Posner, 2015; Tomasino \& } \\
\text { Fabbro, 2015) }\end{array}$ & $\begin{array}{l}\text { Brain correlates of meditation status change its } \\
\text { functional characteristics. }\end{array}$ & $\begin{array}{l}\text { PC guides Qs to control mental } \\
\text { activity and its neural substrate. }\end{array}$ \\
\hline $\begin{array}{l}\text { 3. Hypnosis (Cardeña, Jönsson, Terhune, \& } \\
\text { Marcusson-Clavertz, 2013) }\end{array}$ & $\begin{array}{l}\text { Brain correlates of hypnotic suggestions change } \\
\text { the associated brain functional characteristics. }\end{array}$ & $\begin{array}{l}\text { PC guides Qs to follow the hypnotic } \\
\text { suggestions. }\end{array}$ \\
\hline 4. Placebo (Stewart-Williams, \& Podd, 2004) & $\begin{array}{l}\text { Brain correlates of expectations activate their } \\
\text { brain and physiological correlates. }\end{array}$ & $\begin{array}{l}\text { PC guides Qs to affect physiology as } \\
\text { expected. }\end{array}$ \\
\hline 5. Meta-awareness (Schooler, 2015) & $\begin{array}{l}\text { The brain describes its contents to itself by an } \\
\text { emerging recurrent feedback. }\end{array}$ & PC reflects on and monitors Qs. \\
\hline $\begin{array}{l}\text { 6. Feeling of personal ownership of one's } \\
\text { mental states (Klein, 2015) }\end{array}$ & $\begin{array}{l}\text { Brain damages and induced brain activity } \\
\text { modifications affect Qs. }\end{array}$ & $\begin{array}{l}\text { Brain damages and induced brain } \\
\text { activity modifications affect how PC } \\
\text { realizes Qs. }\end{array}$ \\
\hline $\begin{array}{l}\text { 7. Meta-cognition (Dunlosky \& } \\
\text { Metcalfe, 2008) }\end{array}$ & $\begin{array}{l}\text { The brain can describe its contents to itself by an } \\
\text { emerging recurrent feedback. }\end{array}$ & PC can reflect on and monitor Qs. \\
\hline 8. Mind-wandering (Schooler et al., 2011) & $\begin{array}{l}\text { The brain can describe its contents to itself by an } \\
\text { emerging recurrent feedback. }\end{array}$ & PC can reflect on and monitor Qs. \\
\hline 9. Awareness of flow of time (Block, 2014) & $\begin{array}{l}\text { The brain can describe its contents to itself by an } \\
\text { emerging recurrent feedback. }\end{array}$ & PC can reflect on and monitor Qs \\
\hline $\begin{array}{l}\text { 10. Lucid dreams (Gackenbach \& } \\
\text { LaBerge, 2012). }\end{array}$ & $\begin{array}{l}\text { The brain can describe its dream content to itself } \\
\text { by an emerging recurrent feedback. }\end{array}$ & $\begin{array}{l}\text { PC-guided Qs can reflect on and } \\
\text { monitor dream content. }\end{array}$ \\
\hline $\begin{array}{l}\text { 11. Free will (Bode at al., 2014; } \\
\text { Haggard, 2008) }\end{array}$ & $\begin{array}{l}\text { It emerges from nondeterministic patterns of } \\
\text { brain activity. }\end{array}$ & $\begin{array}{l}\text { PC is not bound by the causal chain } \\
\text { of cognitive and motor processes. }\end{array}$ \\
\hline 12. Bistable perceptions (Kim \& Blake, 2005) & $\begin{array}{l}\text { Qs differences correspond to different brain } \\
\text { activity patterns. }\end{array}$ & $\begin{array}{l}\text { PC realizes Qs differences by } \\
\text { interpreting different brain activity } \\
\text { patterns. }\end{array}$ \\
\hline $\begin{array}{l}\text { 13. Qs with a partial brain (Forsdyke, 2015; } \\
\text { Muckli, Naumer, \& Singer, 2009). }\end{array}$ & $\begin{array}{l}\text { Cognitive functions reorganize their neural } \\
\text { networks. }\end{array}$ & $\begin{array}{l}\text { PC may realize Qs by using the } \\
\text { partial brain. }\end{array}$ \\
\hline $\begin{array}{l}\text { 14. Left vs right hemisphere Qs differences in } \\
\text { split-brain (Gazzaniga, 2005) }\end{array}$ & $\begin{array}{l}\text { The left brain's specialization allows it to describe } \\
\text { its own and the right brain's contents to itself. }\end{array}$ & $\begin{array}{l}\text { PC realizes Qs by using the left } \\
\text { hemisphere in split-brain patients. }\end{array}$ \\
\hline $\begin{array}{l}\text { 15. Nontraumatic or induced with specific } \\
\text { brain stimulation out-of-body experiences } \\
\text { (Carruthers, 2015) }\end{array}$ & $\begin{array}{l}\text { They emerge from the activity of specific brain } \\
\text { networks. }\end{array}$ & $\begin{array}{l}\text { PC Qs are dissociated from the body, } \\
\text { but not from the brain. }\end{array}$ \\
\hline $\begin{array}{l}\text { 16. Near-death experiences (Facco, Agrillo, \& } \\
\text { Greyson, 2015; Nelson, 2014) }\end{array}$ & $\begin{array}{l}\text { Near-death experiences are a byproduct of the } \\
\text { residual brain activity during and after cardiac arrest. }\end{array}$ & $\begin{array}{l}\text { PC remains active even with a } \\
\text { reduced and altered brain activity. }\end{array}$ \\
\hline $\begin{array}{l}\text { 17. Nontraumatic mystical experiences } \\
\text { (Wulff, 2014). }\end{array}$ & $\begin{array}{l}\text { They emerge from the activity of specific brain } \\
\text { networks. }\end{array}$ & $\begin{array}{l}\text { PC-guided Qs interact symbolically } \\
\text { with its origin. }\end{array}$ \\
\hline
\end{tabular}

also be nonverbal. We prefer Q instead of "Consciousness" because the term Consciousness is often used to define both an ontological state and a state of mind.

Independently of every philosophical point of view, regardless of scholarly philosophical theories positing that Qs are merely illusions and we are simply "zombies" (e.g., Wegner, 2004), there is no doubt that without Qs there cannot be any sort of overt (explicit) knowledge of the inner (mental) and outer worlds even if it is still possible to show very advanced adaptive behaviors like that observed in modern robots. Consequently, if an organism has explicit knowledge, then it is not possible that the it does not have Qualia. Qs hence became a necessary condition for explicit knowledge of mental and external events.
How is it possible to have experiences of this kind? In the following, we will compare two competing types of theories. The first one, based on physicalist metaphysics, postulates that Qs are nothing but (eliminative reductionism) or an emerging (constitutive reductionism) neural activity of brain activity triggered by external and internal processes (e.g., Schwartz, Lilienfeld, Meca, \& Sauvigné, 2016). Eliminative reductionism, at its core, subsumes that all mental phenomena can be explained by the functioning of their neurological correlates, which will make superfluous any mental interpretation of all human and nonhuman behaviors. Differently, emerging reductionism postulates that at some level of complex interactions among the low-level brain components, higher level of brain functioning with different properties with 
respect to their constituents, for example, motives, emotions, and personality traits, will come out which could also influence causally the underlying brain activity.

The second one, based on interactionist metaphysics, postulates that Qs arise by an interaction between a nonlocal protoconsciousness (PC) or proto-mind, which interacts as an "Interpreter" using Gazzaniga's terminology ${ }^{1}$ (Gazzaniga, 2011; Roser \& Gazzaniga, 2006), and a "Decision Maker" with the neural information produced by the brain activity. As PC we mean a mind-like primordial substance, the physical laws of which have yet to be investigated (see paragraph $3.1 \mathrm{PC}$ Research Agenda), similar to the description put forward by Hameroff and Penrose (2014) and Beauregard (2014).

An alternative to an interactionist metaphysics, but which forecast the same effects as due to the primacy of a mental versus a material substrate, is the mental monism with all its variants, idealism, panpsychism, and the more recent nonphysical realism (Staune, 2013) and dual-aspect monism (Atmanspacher, 2012) metaphysics.

These two competing theories are represented in Figure 1. Interactive theories like this one are not new in the debate about mind-brain relationships (Zalta, 2013). We may cite Popper and Eccles's (2012; "The Self and Its Brain") theory as an example or the more recent Mario Beauregard's (2014) "Theory of Psychelementarity" (TOP). What is new in the present article is the presentation of a list of $Q$ phenomena and how well each competing theory serves as an explanation for them.

At the end of this list, we will confine ourselves to outlining the gaps each theory must fill in order to shed light on how the different $\mathrm{Q}$ phenomena can be explained. We will leave it to the reader to choose which of the two theories is more plausible or, perhaps, just less weird.

It is important to point out that both theories have in common the fact that every $Q$ experience is correlated to a specific and unique neural signature, elicited by the spatial-temporal patterns of brain activity which can be recorded with traditional means, for example, fMRI, EEG, MEG. The crucial difference concerns how $Q$ phenomena relate to brain activity.
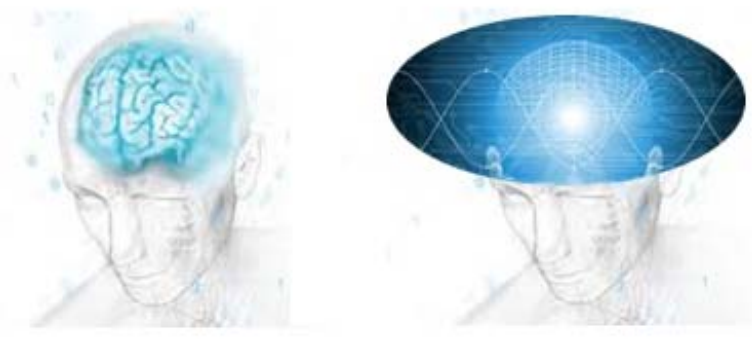

Figure 1. Mind=Brain (left) and Proto-consciousness interacting with the brain (right) schematic representation.

\footnotetext{
1. Even if Gazzaniga's interpretation is that this role is an emerging property of the brain.
}

\section{DIFFERENT QUALIA PHENOMENA TO BE EXPLAINED}

In Table 1, we will illustrate how the two competing theories try to explain different within the body (local) $Q$ experiences. In Table 2, we will present how the two theories try to explain some $\mathrm{Q}$ experiences that are achieved beyond the range of sensory and motor organs (nonlocal). For each of these experiences, we will indicate some references selected in order to offer a more comprehensive explanation.

\section{THE RESEARCH AGENDA}

These research agenda fit well with Chalmers' (2013) project 5 "Systematize the connection" between first-person data and third-person data for the construction of a science of consciousness.

3.1 Research agenda for the PC-Brain connection:

1 What is the physics and biology of the PC-Brain interaction?

2 How does the PC "interpret" brain activity to achieve the different Qs?

3 Is it possible to detect non-Q PC effects?

4 Which is the origin and nature of PC?

Regardless of what the PC is made of, it must exert a physical action on the brain, both for the realization of Qs based on the monitoring of cognitive activities like mind-wandering, metaawareness, and by a process of interpretation of their specific neural correlates and also particularly for the Qs that involve a modification of brain activity (e.g., placebo and meditation). Using Beauregard's term, this relationship must imply a "Psychoneural Transduction Mechanism" (PTM).

A well-known candidate for this PTM is the Orch-OR (Orchestrated-Objective Reduction) theory as proposed by Penrose and Hameroff (Hameroff, 2007, 2012; Hameroff \& Penrose, 2014), which postulates that Qs arise from quantum-like processes $^{2}$ of quantum superposition decoherence between proto-conscious information and the microtubules of brain neurons. A comprehensive description of this theory and its criticisms is beyond the scope of this article but is fully available in the cited references.

Another PTM candidate is the Schwartz, Stapp, and Beauregard's (2005) "Neurophysical Model of Mind." Like the Orch-OR theory, this model is also based on a quantum-like approach. In its essence, this approach is based on the "physics of the observer" as postulated by Von Neumann Wigner and others (Stapp, 2011), that is, on the active and essential role of conscious human choices in the definition of the status of observed (measured) physical properties of nature. The purported mind-brain connection is based on the Zeno effect ${ }^{3}$

2. Interpreting some biological and mental phenomena like those observed in quantum physics.

3. A series of observations after short periods of time affect the probability that the system will be in in a given state, for example, A rather than in state B. In quantum physics, the repeated observation prevents the transition of the system into the decay state. 
Table 2. Nonlocal Q experiences.

\begin{tabular}{|c|c|c|}
\hline Q Experiences & Mind = Brain & Proto-consciousness (PC) $\leftrightarrow$ Brain \\
\hline 1. Nonlocal perception (Tressoldi, 2011) & Impossible & $\begin{array}{l}\text { PC Qs express their nonlocal perceptual } \\
\text { characteristics. }\end{array}$ \\
\hline $\begin{array}{l}\text { 2. Nonlocal interaction with physical targets (Bösch, Steinkamp, \& } \\
\text { Boller, 2006) }\end{array}$ & Impossible & $\begin{array}{l}\text { Some PC Qs express their nonlocal interaction } \\
\text { characteristics. }\end{array}$ \\
\hline $\begin{array}{l}\text { 3. Nonlocal interaction with biological targets (Roe, Sonnex, \& } \\
\text { Roxburgh 2014) }\end{array}$ & Impossible & $\begin{array}{l}\text { Some PC Qs express their nonlocal interaction } \\
\text { characteristics. }\end{array}$ \\
\hline 4. Mediumship (Beischel, Boccuzzi, Biuso, \& Rock, 2015) & Impossible & Some PC Qs survive to the brain. \\
\hline $\begin{array}{l}\text { 5. Witnessed OBEs (Parnia et al., 2014; van Lommel, van Wees, } \\
\text { Meyers, \& Elfferich, 2001) }\end{array}$ & Impossible & PC and brain might separate from each other. \\
\hline
\end{tabular}

that permits "free choices" on the part of an observer to influence his or her brain (Stapp, 2009).

The puzzling neural phenomenon of the anticipation of the neural activity related to free choices with respect to their subjective experience (e.g., Libet, 2006; Soon, He, Bode, \& Haynes, 2013; Soon, Brass, Heinze, \& Haynes, 2008) could be interpreted as a sign of the PTM which requires some time to elicit a $Q$ from the interaction with neural activity.

The attempt to explain some psychological phenomena by referring to the theoretical, mathematical, and statistical tools of quantum physics has already been quite successful in the research field known as "Quantum Cognition" (Bruza, Wang, and Busemeyer, 2015; Pothos \& Busemeyer, 2013). This approach has already proven to be more precise than the classical probability approach in the explanations of some cognitive functions in the reasoning, decision-making, and perception domains.

With respect to the nonlocal Qs, it is quite obvious that the PC too must express nonlocal characteristics-that is, characteristics devoid of space and time boundaries. Is there evidence of a reality where space and time are not absolute and the properties of space- and/or time-separated physical objects may be correlated? This is the apparently weird world of quantum physics, the characteristics of which are not only described at a theoretical level (even if the interpretations are still hotly debated) but supported by overwhelming experimental and technological evidence (e.g., Greenberger, Reiter, \& Zeilinger, 2013; Vedral, 2014)

Is it possible to postulate not only local but also nonlocal quantum-like biological and mental phenomena? This is the frontier of the theoretical and empirical investigation for any PC-brain interaction hypothesis. Fortunately, there are already some contributions of this type to start with. For example, nonlocal spatial and temporal correlations between mental, physical, and biological systems are expected within the Generalized Quantum Theory (Walach \& Römer, 2011; Walach \& von Stillfried, 2011). An attempt to interpret all the more recent empirical evidence related to both nonlocal Qs and implicit behavioral and neurophysiological responses (e.g., Bem, Tressoldi, Rabeyron, \& Duggan, 2015; Mossbridge, Tressoldi, \& Utts, 2012) within this theoretical framework is offered by Walach, Tressoldi, and Pederzoli (2016).

\section{RESEARCH AGENDA FOR THE MIND=BRAIN THEORY}

1 How do first-person $Q$ experiences emerge from the neural patterns of the brain?

2 Do Qs emerge only from the neural patterns of the brain or also from other artificial complex physical signals?

3 How can these Qs causally change brain activity?

4 How can nonlocal mind phenomena be explained?

5 How do Qs become reorganized with a partial innate brain?

6 How do "free" choices emerge from nondeterministic neural patterns?

The above is a research agenda somewhere in between the radical hypothesis that Qs are mere illusions (like free will), and the quite pessimistic agenda put forth by Adolphs (2015) (who situates the question, "How and why does conscious experience arise?" in the "we may never solve" category) and Uttal (2016) whose conclusions states: "At the present time, my overall conclusion is that searching for the neural foundations of cognitive mechanisms (i.e., developing an overarching neuroreductionist theory of the mind using macroneural techniques) is a goal unlikely to be achieved. The use of fMRI systems to explain how the brain produces mental activity is simply being carried out at the wrong level of analysis. I agree with Page (2006), who asserted ... the huge investment of time and money that has accompanied this trend [functional brain imaging] has not resulted in a corresponding theoretical advancement, at least with respect to cognitive psychological theory" (Uttal, 2016, p. 428).

A complete description of all theoretical and empirical approaches currently active exceeds the scope of the present article; hence, we will describe only a selection of them. Further information is available from Seth (2007).

Cleeremans' "Radical Plasticity Thesis" postulates that "The brain continuously and unconsciously learns to redescribe its own activity to itself, so developing systems of meta-representations that characterize and qualify the target first-order 
representations. Such learned redescriptions, enriched by the emotional value associated with them, form the basis of conscious experience" (Cleeremans, 2011, p. 1).

Another well-known theory is Dehaene's "Global Neuronal Workspace Theory" (Baars, 2002; Dehaene, 2014). The core of this theory is that Qs emerge from a nonlinear activity of a complex neural network constituted by long-range corticocortical connections related to sensory and cognitive processes according to their salience.

Tononi and Koch's (2015) "Integrated Information Theory" (IIT) holds that consciousness is a fundamental property possessed by physical systems having specific properties, for example, with a cause-effect power, with cause-effect structure and with a conceptual structure.

Given that according to the above theories-and all those that postulate a mind/brain identity-brain activity is regulated only by linear and nonlinear information processing regulated by classical physics, nonlocal Qs are completely at odds because they violate the spatial and temporal boundaries of classical communication.

\section{FINAL CONSIDERATIONS}

The emergence of Qs and their functions are at the core of every theory of consciousness. In this article, we compared the explanatory power and future research agenda of two opposing types of theories to explain a list of local and nonlocal $\mathrm{Q}$ experiences.

The best type of theory must explain all of the $Q$ experiences listed in Tables 1 and 2 .

In light of the available evidence and the actual explanatory power, which is the weirder?

\section{ACKNOWLEDGEMENTS}

We thank Prof. Carlo Umiltà for his important suggestions in relation to a previous version of this article and Cinzia Evangelista for her English revisions.

\section{REFERENCES}

Adolphs, R. (2015). The unsolved problems of neuroscience. Trends in Cognitive Sciences, 19(4), 173-175. doi:10.1016/j.tics.2015.01.007

Atmanspacher, H. (2012). Dual-aspect monism à la Pauli and Jung. Journal of Consciousness Studies, 19, 96-120.

Baars, B. J. (2002). The conscious access hypothesis: Origins and recent evidence. Trends in Cognitive Sciences, 6(1), 47-52. doi:10.1016/S1364-6613(00)01819-2

Beischel, J., Boccuzzi, M., Biuso, M., \& Rock, A. J. (2015). Anomalous information reception by research mediums under blinded conditions II: Replication and extension. EXPLORE: The Journal of Science and Healing, 11(2), 136-142. doi:10.1016/j.explore.2015.01.001

Bem, D. J., Tressoldi, P. E., Rabeyron, T., \& Duggan, M. (2015). A metaanalysis of 90 experiments on the anomalous anticipation of random future events. F1000Research, 4, 1188. doi:10.12688/ f1000research.7177.1

Beauregard, M. (2014). The primordial psyche. Journal of Consciousness Studies, 21(7-8), 132-157.
Block, R. A. (2014). Cognitive models of psychological time. Psychology Press. Hove, UK.

Bode, S., Murawski, C., Soon, C. S., Bode, P., Stahl, J., \& Smith, P. L. (2014). Demystifying "free will": The role of contextual information and evidence accumulation for predictive brain activity. Neuroscience \& Biobehavioral Reviews, 47, 636-645. doi:10.1016/ j.neubiorev.2014.10.017

Bösch, H., Steinkamp, F., \& Boller, E. (2006). Examining psychokinesis: The interaction of human intention with random number generators-A meta-analysis. Psychological Bulletin, 132(4), 497-523. doi:10.1037/0033-2909.132.4.497

Bruza, P. D., Wang, Z., \& Busemeyer, J. R. (2015). Quantum cognition: A new theoretical approach to psychology. Trends in cognitive sciences, 19(7), 383-393. doi:10.1016/j.tics.2015.05.001

Cardeña, E., Jönsson, P., Terhune, D. B., \& Marcusson-Clavertz, D. (2013). The neurophenomenology of neutral hypnosis. Cortex, 49 (2), 375-385. doi:10.1016/j.cortex.2012.04.001

Carruthers, G. (2015). Who am I in out of body experiences? Implications from OBEs for the explanandum of a theory of selfconsciousness. Phenomenology and the Cognitive Sciences, 14(1), 183-197. doi:10.1007/s11097-013-9332-0

Chalmers, D. J. (2013). How can we construct a science of consciousness? Annals New York Academy of Science, 1303, 25-35. doi:10.1111/nyas.12166

Churchland, P. M. (2013). Matter and consciousness. MIT press. Cambridge MA, USA

Cleeremans, A. (2011). The radical plasticity thesis: How the brain learns to be conscious. Frontiers in Psychology, 2, 86. doi:10.3389/ fpsyg.2011.00086

Cohen, J. D., \& Schooler, J. W. (2014). Scientific approaches to consciousness. Psychology Press. Hove, UK.

Dehaene, S. (2014). Consciousness and the brain: Deciphering how the brain codes our thoughts. Penguin. N.Y., USA.

Dunlosky, J., \& Metcalfe, J. (2008). Metacognition. Sage. Thousand Oaks, CA, USA

Facco, E., Agrillo, C., \& Greyson, B. (2015). Epistemological implications of near-death experiences and other non-ordinary mental expressions: Moving beyond the concept of altered state of consciousness. Medical Hypotheses, 85(1), 85-93. doi:10.1016/j. mehy.2015.04.004

Forsdyke, D. R. (2015). Wittgenstein's certainty is uncertain: Brain scans of cured hydrocephalics challenge cherished assumptions. Biological Theory, 10(4), 336-342. doi:10.1007/s13752-0150219-x

Gazzaniga, M. S. (2005). Forty-five years of split-brain research and still going strong. Nature Reviews Neuroscience, 6(8), 653-659. doi:10.1038/nrn1723

Gazzaniga, M. S. (2011). Who is in charge? BioScience, 61(12), 937-938. doi:10.1525/bio.2011.61.12.2

Gackenbach, J., \& LaBerge, S. (Eds.). (2012). Conscious mind, sleeping brain: Perspectives on lucid dreaming. Springer Science \& Business Media. N.Y., USA.

Greenberger, D., Reiter, W. L., \& Zeilinger, A. (Eds.). (2013). Epistemological and experimental perspectives on quantum physics (Vol. 7). Springer Science \& Business Media. N.Y., USA.

Haggard, P. (2008). Human volition: Towards a neuroscience of will. Nature Reviews Neuroscience, 9(12), 934-946. doi:10.1038/ nrn2497

Hameroff, S. (2012). How quantum brain biology can rescue conscious free will. Frontiers in Integrative Neuroscience, 6, 93. doi:10.3389/ fnint.2012.00093

Hameroff, S., \& Penrose, R. (2014). Consciousness in the universe: A review of the 'Orch OR'theory. Physics of Life Reviews, 11(1), 39-78. doi:10.1016/j.plrev.2013.08.002 
Hameroff, S. R. (2007). The brain is both neurocomputer and quantum computer. Cognitive Science, 31(6), 1035-1045. doi:10.1080/ 03640210701704004

Kim, C. Y., \& Blake, R. (2005). Psychophysical magic: Rendering the visible 'invisible'. Trends in Cognitive Sciences, 9(8), 381-388. doi:10.1016/j.tics.2005.06.012

Klein, S. (2015). The feeling of personal ownership of one's mental states: A conceptual augment and empirical evidence for an essential, but underappreciated, mechanism of mind. Psychology of Consciousness: Theory, Research, and Practice, 2(4), 355-376. doi:10.1037/cns0000052

Libet, B. (2006). Reflections on the interaction of the mind and brain. Progress in Neurobiology, 78(3), 322-326. doi:10.1016/j.pneurobio. 2006.02.003

Messina, I., Sambin, M., Palmieri, A., \& Viviani, R. (2013). Neural correlates of psychotherapy in anxiety and depression: a meta-analysis. PLoS One, 8(9), e74657. doi:10.1371/journal.pone.0074657

Michael, T. (2015). "Qualia," The Stanford encyclopedia of philosophy (fall 2015 Edition). In E. N. Zalta (Ed.), Retrieved August 28, 2016, from http://plato.stanford.edu/archives/fall2015/entries/qualia/

Mossbridge, J., Tressoldi, P., \& Utts, J. (2012). Predictive physiological anticipation preceding seemingly unpredictable stimuli: A metaanalysis. Frontiers in Psychology 3, 390. doi:10.3389/fpsyg.2012. 00390

Muckli, L., Naumer, M. J., \& Singer, W. (2009). Bilateral visual field maps in a patient with only one hemisphere. Proceedings of the National Academy of Sciences, 106(31), 13034-13039. doi:10.1073/pnas. 0809688106

Nelson, K. R. (2014). Near-death experience: Arising from the borderlands of consciousness in crisis. Annals of the New York Academy of Sciences, 1330(1), 111-119. doi:10.1111/nyas.12576

Page, M. P. A. (2006). What can't functional neuroimaging tell the cognitive psychologist? Cortex, 42(3), 428-443. doi:10.1016/ S0010-9452(08)70375-7

Parnia, S., Spearpoint, K., de, V. G., Fenwick, P., Goldberg, D., Yang, J., et al. (2014). AWARE-AWAreness during REsuscitation-A prospective study. Resuscitation, 85(12), 1799-1805. doi:10.1016/j. resuscitation.2014.09.004

Popper, K. R., \& Eccles, J. C. (2012). The self and its brain. Springer Science \& Business Media. N.Y., USA.

Pothos, E. M., \& Busemeyer, J. R. (2013). Can quantum probability provide a new direction for cognitive modeling? Behavioral and Brain Sciences, 36(03), 255-274. doi:10.1017/S0140525X12001525

Roe, C. A., Sonnex, C., \& Roxburgh, E. C. (2014). Two meta-analyses of noncontact healing studies. EXPLORE: The Journal of Science and Healing, 11, 11-23. doi:10.1016/j.explore.2014.10.001

Roser, M. E., \& Gazzaniga, M. S. (2006). The interpreter in human psychology. Oxford: The Evolution of Primate Nervous Systems.

Schooler, J. (2015). Bridging the objective/subjective divide. Towards a meta-perspective of science and experience. In T. Metzinger \& J. M. Windt (Eds.), Open MIND: 34(T). Frankfurt am Main: MIND Group.

Schooler, J. W., Smallwood, J., Christoff, K., Handy, T. C., Reichle, E. D., \& Sayette, M. A. (2011). Meta-awareness, perceptual decoupling and the wandering mind. Trends in Cognitive Sciences, 15(7), 319-326. doi:10.1016/j.tics.2011.05.006

Schwartz, J. M., Stapp, H. P., \& Beauregard M. (2005). Quantum physics in neuroscience and psychology: A neurophysical model of mindbrain interaction. Philosophical Transactions of the Royal Society B. 360, 1309-1327. doi:10.1098/rstb.2004.1598:1-19

Schwartz, S. J., Lilienfeld, S. O., Meca, A., \& Sauvigné, K. C. (2016). The role of neuroscience within psychology: A call for inclusiveness over exclusiveness. The American Psychologist, 71(1), 52-70. doi:10.1037/a0039678
Seth, A. (2007). Models of consciousness. Scholarpedia, 2(1), 1328. doi:10.4249/scholarpedia.132

Soon, C. S., Brass, M., Heinze, H. J., \& Haynes, J. D. (2008). Unconscious determinants of free decisions in the human brain. Nature Neuroscience, 11(5), 543-545. doi:10.1038/nn.2112

Soon, C. S., He, A. H., Bode, S., \& Haynes, J. D. (2013). Predicting free choices for abstract intentions. Proceedings of the National Academy of Sciences, 110(15), 6217-6222. doi:10.1073/pnas.1212218110

Stapp, H. P. (2009). A model of the quantum-classical and mind-brain connections, and the role of the quantum Zeno effect in the physical implementation of conscious intent. In Springer Verlag (Ed.), Mind, Matter and Quantum Mechanics (pp. 261-273). Berlin, Germany: Springer.

Stapp, H. P. (2011). Mindful universe: Quantum mechanics and the participating observer. Springer Science \& Business Media. N.Y., USA.

Staune, J. (2013). Towards non-physical realism. In A. Suarez, \& P. Adams (Eds.), Is science compatible with free will? (pp. 209-224). New York: Springer.

Stewart-Williams, S., \& Podd, J. (2004). The placebo effect: Dissolving the expectancy versus conditioning debate. Psychological Bulletin, 130(2), 324. doi:10.1037/0033-2909.130.2.324

Tang, Y. Y., Hölzel, B. K., \& Posner, M. I. (2015). The neuroscience of mindfulness meditation. Nature Reviews Neuroscience, 16(4), 213225. doi:10.1038/nrn3916

Tomasino, B., \& Fabbro, F. (2015). Editorial: Neuroimaging and neuropsychology of meditation states. Frontiers in Psychology, 6, 1757. doi:10.3389/fpsyg.2015.01757

Tononi, G., \& Koch, C. (2015). Consciousness: Here, there and everywhere? Philosophical Transactions of the Royal Society B, 370, 20140167. doi:10.1098/rstb.2014.0167

Tressoldi, P. E. (2011). Extraordinary claims require extraordinary evidence: The case of non-local perception, a classical and Bayesian review of evidences. Frontiers in Psychology, 2, 117. doi:10.3389/ fpsyg.2011.00117

Uttal, W.R. (2016). Macroneural theories in cognitive neuroscience. Psychology Press. Hove, UK.

Vedral, V. (2014). Quantum entanglement. Nature Physics, 10(4), 256258. doi: $10.1038 /$ nphys 2904

Walach, H., \& Römer, H. (2011). Generalized entanglement - A nonreductive option for a phenomenologically dualist and ontologically monist view of consciousness. In H. Walach, S. Schmidt, \& W. B. Jonas (Eds.), Studies in neuroscience, consciousness and spirituality. Springer Science. N.Y., USA.

Walach, H., \& von Stillfried, N. (2011). Generalised quantum theory Basic idea and general intuition: a background story and overview. Axiomathes, 21(2), 185-209. doi:10.1007/s10516-010-9145-5

Walach, H., Tressoldi, P. E., \& Pederzoli, L. (2016). Mental, behavioural and physiological nonlocal correlations within the generalized quantum theory framework: A review. Axiomathes, 26(3), 313-328.

van Lommel, P., van Wees, R., Meyers, V., \& Elfferich, I. (2001). Neardeath experience in survivors of cardiac arrest: a prospective study in the Netherlands. Lancet, 358(9298), 2039-2045. doi:10.1016/S0140-6736(01)07100-8

Wegner, D. M. (2004). Précis of the illusion of conscious will. Behavioral and Brain Sciences, 27(05), 649-659. doi:10.1017/ S0140525X04000159

Wulff, D. M. (2014). Mystical experience. In E. L. Cardeña, S. Jay, S. Krippner (Eds.), Varieties of anomalous experience: Examining the scientific evidence (2nd ed.). American Psychological Association. Washington, USA.

Zalta, E. N. (2013). The Stanford Encyclopedia of Philosophy. The Metaphysics Research Lab Center for the Study of Language and Information, Stanford University. Retrieved August 29, 2016, from http://plato.stanford.edu 


\section{COMPETING INTERESTS}

The authors declare no competing interests.

\section{PUBLISHING NOTES}

(C) 2016 Tressoldi et al. This work has been published open access under Creative Commons Attribution License CC BY 4.0, which permits unrestricted use, distribution, and reproduction in any medium, provided the original work is properly cited. Conditions, terms of use and publishing policy can be found at www.scienceopen.com.
Please note that this article may not have been peer reviewed yet and is under continuous post-publication peer review. For the current reviewing status please click here or scan the QR code on the right.

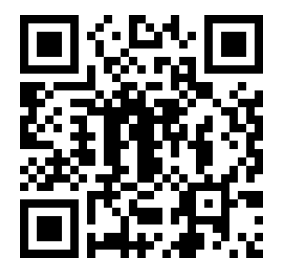

\section{scienceOPEN.com}

